\title{
Cigar magazines: using tobacco to sell a lifestyle
}

\author{
Lynn D Wenger, Ruth E Malone, Annie George, Lisa A Bero
}

Institute for Health

Policy Studies,

University of

California, San

Francisco, San

Francisco, California,

USA

L D Wenger

A George

Institute for Health

Policy Studies,

Department of Clinical

Pharmacy, and

Department of

Physiological Nursing,

University of

California, San

Francisco

R E Malone

Institute for Health

Policy Studies and

Department of Clinical

Pharmacy, University

of California, San

Francisco

L A Bero

Correspondence to:

Ruth Malone, $\mathrm{PhD}$,

University of California San

Francisco, Institute for

Health Policy Studies, Box

0936, Laurel Heights, San

Francisco, CA 94143-0936,

USA

rmalone@itsa.ucsf.edu

Received 30 October 2000 and in revised form

27 April 2001. Accepted 3

May 2001

\begin{abstract}
Objective-To assess the content of two cigar "lifestyle" magazines, Cigar Aficionado and Smoke.
\end{abstract}

Design-Content analysis of cigar focused articles.

Subjects-Cigar focused articles $(n=353)$

from Cigar Aficionado and Smoke magazines.

Main outcome measures-Primary focus; mention of health effects, environmental tobacco smoke, or scientific research; quotation and description of individuals; characteristics such as sex, age, ethnicity, smoking status, affiliation, and stance towards cigars; and overall image of cigars.

Results-Cigar business-focused articles were the largest category $(40 \%, n=143)$, followed by articles about cigar events $(12 \%, n=42)$. Notable were articles featuring cigar benefits to raise money for health charities. Celebrities were featured in $34 \%(n=121)$ of articles and $96 \%$ ( $n=271)$ favoured cigar use. Only four (1\%) articles featured health effects of cigars as a primary focus.

Conclusions-Cigar Aficionado and Smoke broke new ground in tobacco marketing by combining promotion of product, lifestyle, and industry in the same vehicle and linking the medium directly to product related events that extended its reach. The creation and marketing of new tobacco use sites challenges the increasing "isolation" of smokers, and positions cigar use as a socially welcome relief from restrictions. Public health advocates should anticipate and challenge other new tobacco marketing vehicles as communications technologies advance and public spaces for smoking shrink. (Tobacco Control 2001;10:279-284)

Keywords: cigars; cigar magazines; lifestyles; tobacco marketing

Compared to non-smokers, cigar smokers are at increased risk for cancer, heart disease, and pulmonary disease and have higher mortality from any cause. ${ }^{12}$ Passive cigar smoke may also be a health risk. ${ }^{3}$ Despite these health risks, during the late 1990 s, cigar sales increased by more than $50 \%$. This increase was due almost exclusively to the rising sales of large cigars. ${ }^{4}$ Surveys among California adults, between 1990 and 1996, showed that the increase in cigar smoking occurred primarily among younger, more educated adults. ${ }^{5}$ Additionally, widespread use of cigars, especially relatively cheap, machine made cigars, has been found among teenagers. ${ }^{6}$ Cigar bars, cigar clubs, cigar nights at restaurants, and cigar specialty stores appeared in major cities. Cigar sites marketed cigars on the internet. ${ }^{7}$ Amid this trend, two cigar magazines, Cigar Aficionado and Smoke, appeared on US newsstands. We conducted a content analysis of Cigar Aficionado and Smoke magazines to learn more about what they contributed to the cigar use trend.

In Cigar Aficionado and Smoke, cigars appeared as an integral part of a successful, sophisticated lifestyle. The notion of "lifestyle" as an identity has come into currency only in the past two decades. According to the Oxford English Dictionary, Alfred Adler used the term as early as the 1920 s to mean a person's basic character, established early in life, which governs reactions and behaviour. ${ }^{8}$ By 1973, the definition and use of the term lifestyle had shifted to describe an identity chosen by an individual ${ }^{8}$. As currently understood in the field of health promotion, lifestyle implies a set of behaviours typical for an individual or group. ${ }^{9}$ Social theorists understand lifestyle as a means of social stratification, positioning people in an economically defined class structure. In classical sociological theory, the concept of lifestyle denotes a pattern of conduct, habits, and orientations for the individual, an expression of belonging to a particular group, and some suggestions of structured life chances. ${ }^{9} 10$

Lifestyle as "identity" has significant implications for marketing. Lifestyles become associated with consumption of specific goods and services. Product involvement, according to consumer behaviour theorists, occurs when a consumer product is linked with a person's values and self concept. ${ }^{11}$ An "upscale" lifestyle includes consumption of high priced consumer goods that connote luxury, sophistication, and style. Lifestyles are creations of markets and media, mutually reinforcing each other through a cycle of advertising images that arouse consumptive desires to fashion a self compatible with a particular lifestyle. ${ }^{910}$ Lifestyle magazines combine structural features of the "lifestyle" concept with consumers' aspirational choices in one package. As Marshall McLuhan predicted over 30 years ago, the medium becomes the message. ${ }^{12}$

Lifestyle magazines, which have been called "magalogs", are "merchandising devices for corporations ... .designed to reach customers directly and to treat every page as a marketing opportunity". ${ }^{13}$ "Lifestyle" magazines market a variety of lifestyles that revolve around travel (Travel and Leisure), golf (Backspin), cars (VM 
The Vauxhaul Magazine), alcohol (Wine Spectator), and cigars (Cigar Aficionado and Smoke). The wine and cigar magazines, however, were perhaps the first lifestyle magazines to focus entirely on a single product.

Cigar Aficionado and Smoke depict a lifestyle in which cigars and other luxury products play an integral part in achieving a "successful" identity. The editorial in the premier issue of Cigar Aficionado, which appeared in September 1992, stated: "Cigar Aficionado is about taste. But it is not limited to the taste of a great smoke. This magazine intends to awaken and explore many of the pleasures that drive successful men". ${ }^{14}$ From the outset, Cigar Aficionado was marketed as a lifestyle magazine, aimed at those who had the money to buy the best products and those who aspired to do so.

Cigar Aficionado and Smoke magazines are still in circulation. They are both still glossy magazines with celebrities pictured on the covers. Cigar Aficionado's circulation peaked in 1997 at 400115 and has declined somewhat since; however, in 1998, Cigar Aficionado still had a circulation of over $300000 . .^{15}$ Cigar Aficionado has recently redesigned the magazine in order to attract new readers who are interested in the "lifestyle" promoted in the magazine. The size of the word "cigar" in the logo that appears on the cover of the magazine has been reduced significantly, cigar ratings and cigar stories have been moved to the back of the magazine, and the "lifestyle" editorials to the front ${ }^{16}$. Smoke circulation size ranged from 85489 in $1996^{17}$ to 143151 in 1998 and, to date, has not gone through any major design changes.

It is debatable whether Cigar Aficionado started or simply took advantage of the cigar trend that appeared to be part of a carefully planned marketing strategy. ${ }^{18}$ Industry leaders began meeting in 1980 to plan a public relations campaign in which cigars would be repositioned as a status symbol. A major part of the campaign included placement of news and feature stories in mass media outlets in order to keep coverage of cigars before the public and show them in a positive light. The

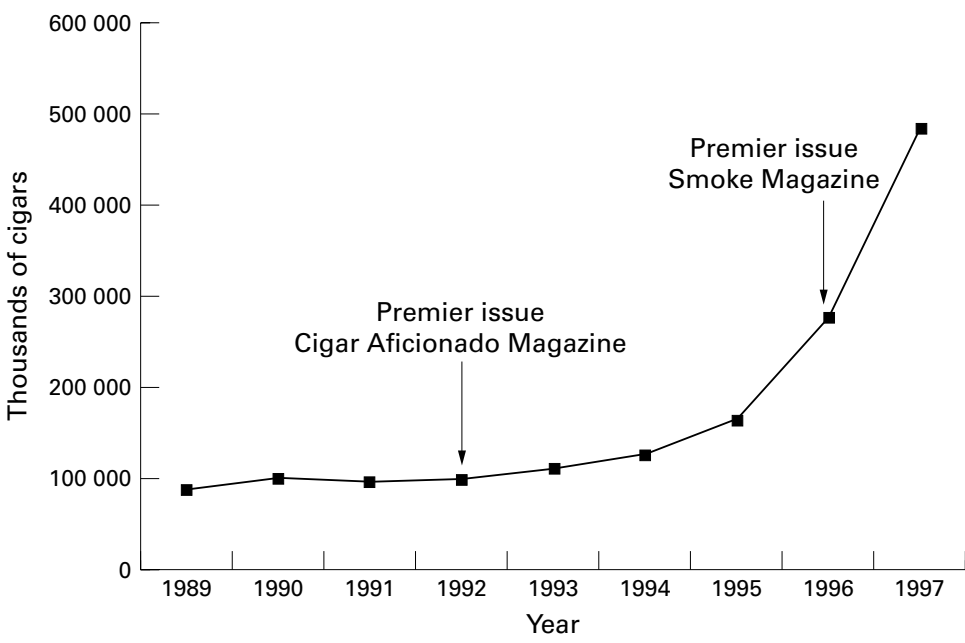

Figure 1 Total sales of premium cigars for eight key supplier countries. industry also used cigar dinners, cigar bars, and celebrity associations strategically to promote their products. ${ }^{18}$ In 1990, after years of low activity, US sales of premium cigars had nearly tripled from their 1987 level (fig 1). ${ }^{19}$ Since then, sales of cigars and cigar related products have increased further. In 1998, the per capita cigar consumption in the US of large and little cigars was 20, up from 14 in 1992 when Cigar Aficionado was launched. During the same period, annual male per capita cigar consumption rose from 41 to $59 .^{20}$

As part of a larger study of the media's role in the cigar trend, in which we found extensive media coverage of cigars that was largely favourable and minimised the health risks of smoking, ${ }^{21}$ we conducted a content analysis of Cigar Aficionado and Smoke.

\section{Methods}

We attempted to obtain all issues of each magazine by subscribing to them and borrowing back issues. Some issues of Cigar Aficionado were out of print and we could not find anyone who owned them. We obtained 19 of the 26 Cigar Aficionado issues published between January 1992 and June 1998. We obtained all 11 issues of Smoke beginning with Spring 1996 and ending with the June 1998 issue.

We hand searched each issue to identify cigar focused articles (articles in which the subject of the article was cigars, cigar accessories, or cigar events) $(\mathrm{n}=353)$. In Cigar Aficionado, $60 \%$ (271/462) of the articles were not focused on cigars; in Smoke 57\% (221/389) of the articles did not focus on cigars. These non-cigar focused articles covered luxury topics such as art, sports, music, fashion, gambling, jewellery, collectibles, and leisure.

One coder coded each cigar focused article using a semi-structured instrument adapted from a previous study. ${ }^{21}$ We developed the coding categories inductively by reading articles that were not included in this sample. We coded the primary focus of each article into mutually exclusive categories to determine the potential audience appeal of the article. We examined whether health effects, environmental tobacco smoke (ETS), and scientific research were mentioned. We also coded whether or not individuals, including celebrities and public figures, were quoted and described in the article, and identified characteristics such as their sex, age, ethnicity, smoking status, affiliation, and their stance towards cigars. Finally, using a seven point Likert-type scale, we assessed whether the article portrayed an overall positive, neutral, or negative image of cigars. An article coded as having a positive image meant that cigars were portrayed in a favourable way - for example, as enjoyable, profitable, fashionable or relaxing. An article coded as having a negative image meant that cigars were portrayed in an unfavourable way - for example, as harmful or unpleasant. Since there were no major differences between the two magazines, we combined the data for presentation. Data were entered into Microsoft Access database and analysed using SAS. ${ }^{22}$ 


\section{Results}

PRIMARY FOCUS OF ARTICLES

As shown in table 1, articles on the cigar business made up the largest category (40\%; $n=143$ ) of the cigar focused articles. This category included articles about cigar manufacturing, marketing and sales, introduction of new cigars, tobacco cultivation techniques, and individuals' experiences working in tobacco fields. Many of these articles were interviews with individuals involved in the cigar industry, focusing on their business successes.

For example, the summer 1995 issue of Cigar Aficionado featured an article entitled "The world's best wrapper" about Cuban cultivation of shade grown tobacco wrapper leaves. The business was portrayed as extremely successful in financial terms, but the article also portrayed the business as socially positive, providing schools, houses, and other social services to its workers. The manager was quoted as saying that the business was run with a "social conscience". ${ }^{23}$ Typical of cigar business success stories was an article in the May/June 1997 issue of Cigar Aficionado, describing the almost overnight success of Ernesto Perez-Carrillo's El Credito Cigar Co. This success was credited to a "sterling" rating of his La Gloria Cubana cigar and a subsequent story about his family-style cigar factory in Cigar Aficionado. In the months following the article he outgrew his factory in Miami where he was manufacturing 1.2 million cigars/year and moved to a large cigar factory in the Dominican Republic manufacturing 6 million cigars/year. ${ }^{24}$

Articles on cigar social events made up 12\% $(n=42)$ of the articles. These events included dinners, lunches, and seminars, where cigar lovers spent time together smoking cigars, eating gourmet food, and drinking premium alcohol. Both magazines reported on cigar events they sponsored. Since 1996, Cigar Aficionado has hosted as many as 10 "Big Smoke" dinners per year. Each event was reported in the magazine as a sell out with mostly male crowds of between 1000 and 3000 people paying $\$ 150$ each. Smoke reported an event it sponsored in 1997 at the New Orleans Hyatt where 420 diners "sat and chatted with representatives from over 25 wine, spirits, cigar manufacturers, and cigar accessory companies for a intimate and civilised evening of entertainment and cigars". ${ }^{25}$ Also featured were the openings of cigar bars, lounges, and shops in the USA and other countries, and a cigar cruise.

Some articles featured benefit events to raise money for various health charities. For instance, in 1995 Cigar Aficionado held a cigar event in Paris, and donated the proceeds from

Table 1 Primary focus of cigar focused articles $(n=353)$

\begin{tabular}{lcr}
\hline & Frequency & $\%$ \\
\hline Cigar business & 143 & 40 \\
Cigar events & 42 & 12 \\
Cigar trend & 2 & $<1$ \\
Health effects of cigars & 4 & 1 \\
Cigar people & 26 & 7 \\
Cigar accessories & 24 & 7 \\
Cigars (including reviews) & 38 & 11 \\
\hline
\end{tabular}

auctions held at the event to Cuba's Medical Relief Fund, and to CapCure, an organisation that funds research for prostate cancer. ${ }^{26}$

Articles about cigars themselves made up $11 \%(\mathrm{n}=38)$ of the cigar focused articles. These articles contained information and opinions about the best and the worst cigars, and ratings of cigars in various categories.

Articles on "cigar people" made up 7\% $(n=26)$ of the cigar focused articles. The cigar people category included individuals in the cigar business, from chief executive officers to cigar rollers, public figures such as John F Kennedy and Thomas Edison, and celebrities who smoked cigars, such as Elvis Presley and George Burns.

HEALTH EFFECTS OF CIGARS

Only $4(1 \%)$ of the cigar focused magazine articles featured the health effects of cigars as a "primary focus". All four of these articles were published in Cigar Aficionado. These articles suggested that the purported "benefits" of cigar smoking (for example, "pleasure" and "relaxation") outweigh health risks. In an article entitled "A grandmother's habit", George Burns, Winston Churchill, and others are described as incessant smokers (10-15 cigars per day) who "lived so long and contributed so much", ${ }^{27}$ implying that these individuals' long lives were attributable to their cigar smoking habits. One article described attempts to organise cigar smokers against "the health police . . .who spend so much time railing about what we should or shouldn't do to our bodies . . . ${ }^{28}$ These articles tended to minimise health risks.

The health effects of cigar smoking were mentioned in only $13(3 \%)$ of magazine articles. When health effects were mentioned, it was again in the context of a "risk/benefit" ratio, where "benefits" were assumed to outweigh risks. In a biography of cigar smoker Sigmund Freud, the author suggested that Freud continued smoking because he felt that the benefits outweighed the risks. However, Freud suffered from cardiac illness and cancer of the mouth and jaw, and was advised by his doctors several times throughout his life to give up cigar smoking. ${ }^{29}$ In an opinion piece about the health risks of cigars entitled "Just the Facts: a doctor examines the links between coronas and coronaries", a psychiatrist also described this risk/benefit ratio.

"What it all comes down to is the risk/benefit ratio. As Sigmund Freud pointed out many years ago, all of us are constantly making decisions, consciously or unconsciously, trying to balance the risk of pain versus the benefit of pleasure in our behaviours ... The unwillingness to face any risk is, in the end, if not impossible, at least an acceptance of a zombie like existence and an abdication of challenge . . obviously, some reasonable degree of prudence in the choice of risk makes sense. But smoking cigars? That would certainly fall in the acceptable category." ${ }^{30}$ It is important to note that this physician, like Freud, is a psychiatrist who smokes cigars. Although his status as a doctor was emphasised (he was even photographed in his white coat 


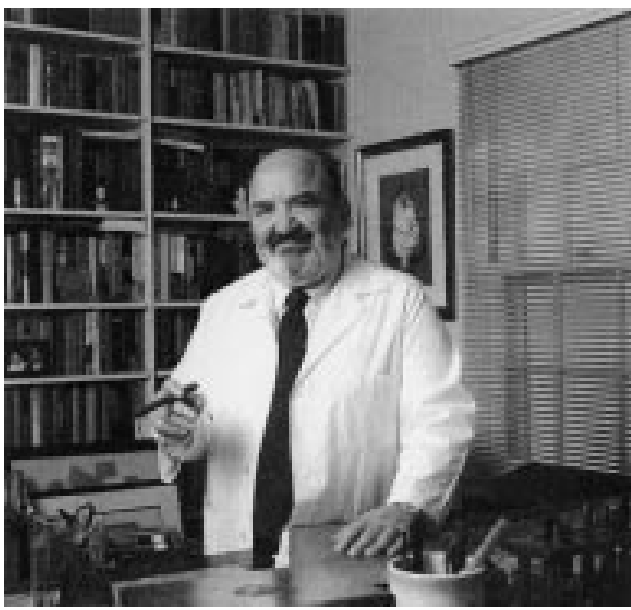

Figure 2 The author (a psychiatrist) of an opinion piece in Cigar Aficionado about the health risks of cigars entitled "Fust the facts: a doctor examines the links between coronas and coronaries". ${ }^{30}$

(fig 2)) at no point were any qualifications as an expert in tobacco related disease described.

Health risks associated with cigar use were also minimised by comparing them to those associated with cigarettes. Edgar Cullman, Jr, president and chief executive officer of Culbro Corporation, one of the largest cigar manufacturers, was quoted in Cigar Aficionado as saying:

"I firmly believe that ... products (cigars) used in moderation can be of benefit to the psyche, to the general well-being of the individual as opposed to real harm. The cigar is consumed in a very different way than the cigarette is. It's consumed without inhaling, it's consumed very infrequently, and it's not a habit. It's a part of a lifestyle." 31

Scientific research on cigars was mentioned in only eight $(2 \%)$ of the articles. When scientific research was mentioned, the evidence was described as "weak". ${ }^{32}$ Studies were described as flawed because they were laboratory experiments, conducted outside of the US, or because they were supposedly outdated. Only one article cited research on cigar use that was considered valid; this was studies of cigar smoking among teenagers, which showed that boys and girls aged 14-19 years had begun smoking cigars. ${ }^{33}$

Similarly, ETS was mentioned in only 12 of the cigar focused articles. ETS was mentioned in one of two ways: either in the context of a discussion of smoking restrictions and how they "deny smokers' rights" or to state that the evidence of the health risks associated with ETS is "weak" and/or "contradictory".

INDIVIDUALS QUOTED AND DESCRIBED

Individuals were quoted and described in $80 \%$ $(n=282)$ of the articles. Excluding celebrities and public figures, we found 1612 mentions of individuals, mostly men. Age and ethnicity were rarely mentioned. The majority (95\%; $394 / 414$ ) of individuals identified as smokers smoked cigars. Fifty six per cent of the individuals $(n=908)$ were affiliated with the tobacco industry, while only $3 \%(n=45)$ were affiliated with public health programmes. Eighty two per cent $(n=1329)$ were portrayed as favourable towards cigars (table 2).
Table 2 Individuals quoted and/or described in cigar focused articles

\begin{tabular}{lrr}
\hline & $\begin{array}{c}\text { Frequency } \\
(n=1612 \text { mentions })\end{array}$ & $\%$ \\
\hline Sex & 1333 & \\
Men & 203 & 83 \\
Women & 69 & 13 \\
Not specified & 6 & 4 \\
Other & & $<1$ \\
Not specified & & \\
& 394 & \\
Smoking status & 1198 & 24 \\
Cigar smoker & 11 & $<1$ \\
Not specified & 9 & $<1$ \\
Non-smokers & & \\
Pipe/cigarette smokers & 908 & 56 \\
Affiliation & 132 & 3 \\
Tobacco industry & 45 & 2 \\
Media/entertainment & 40 & 2 \\
Public health/government & 38 & \\
Hotel restaurant industry & & 82 \\
Business/finance & 1328 & \\
Position regarding cigars & & \\
Favourable & & \\
\hline \multirow{2}{*}{ Affigtion was not identified } & &
\end{tabular}

^Affiliation was not identified for some individuals.

CELEBRITIES AND PUBLIC FIGURES

Three hundred and thirty two different celebrities and public figures were quoted or described in 121 (34\%) of the articles. They were politicians, actors, musicians, painters, writers, and adventurers. Of celebrities whose position towards cigars was specified, 96\% $(n=271)$ were favourable toward cigar use.

Sometimes celebrities were simply mentioned in passing, but usually the articles featured one celebrity and discussed how cigars were part of his or her life. For example, the June 1998 issue of Cigar Aficionado featured actor Michael Douglas on its cover and in the lead article. The most frequently mentioned celebrities were Fidel Castro, Bill Clinton, and John F Kennedy.

IMAGE OF CIGARS PORTRAYED

We rated the image of cigars portrayed in the articles on a scale of 1 to 7 . Ninety two per cent of the articles conveyed a positive image in which cigars were portrayed as pleasurable, relaxing, and part of a successful lifestyle (rated 6 or 7 on the scale). Combining categories 1 and 2 , the negative end of the scale, we found that $<1 \%$ of articles conveyed a negative image of cigars in which cigars were described bad/unpleasant. These articles featured issues such as the arrest and prosecution of cigar smugglers, and a description of how life insurance companies treat cigar and cigarette smokers in the same way by raising premiums for both.

\section{Discussion}

Cigar Aficionado and Smoke provided marketing platforms upon which repositioned visions of the cigar and tobacco industry were built. By associating cigars with a wide range of celebrities (who were highly favourable toward cigars), and by minimisation of cigars' negative effects on health, the magazines normalised and promoted cigar use and implied that they were a constitutive element of a successful lifestyle. Further, their emphasis on the cigar business as socially responsible is in line with 
other recent attempts (for example, the recent Philip Morris campaign) to remake the negative public image of tobacco and the tobacco industry.

When event money is raised for health related organisations, the cigar industry is marketed as socially responsible and supportive of good health while trivialising public health concerns about tobacco use. This positioning is also furthered by the use of medical "experts" who promote cigar use as beneficial. Articles that focus on cigar social events extend the reach of the cigar "magalog" by turning widespread public smoking bans and negative societal attitudes about public smoking to commercial advantage. By creating new public/private spaces and orchestrating social events where cigar smokers can smoke without opprobrium, the industry creates a situation wherein the cigar is seen simultaneously as a symbol of social rebellion and a symbol of social success.

Likewise, it is noteworthy that the only scientific study related to cigars that was portrayed as valid was a study of teen cigar use. This is strategically important for the industry because they are able to condemn youth use while emphasising the social messages that this is a "popular" youth habit and an "adult" choice, all of which make such behaviours more attractive to adolescents. ${ }^{34}$

Tobacco companies have previously sought to promote other products by publishing magazines. For example, Philip Morris sought to reach young adult smokers, who never saw "Marlboro Country" on television, via direct mailing its men's lifestyle magazine Unlimited, ${ }^{356}$, which it launched in 1996 . What is different about the cigar magazines is that they appear prominently on newsstands and are frequently described in the media, and may be the first to make the tobacco product the focus of the entire magazine. These magazines serve simultaneously to market cigar use and reinforce the lifestyle associated with it, creating a symbiosis between product and lifestyle.

This study has several limitations. We were not able to obtain every issue of Cigar Aficionado. Since we conducted a content analysis, we measure exposure to content, but cannot make any conclusions about how the content of these magazines actually influenced behaviour. Further, we do not make direct comparisons to other lifestyle magazines.

Cigar Aficionado and Smoke broke new ground in tobacco marketing by combining unabashed promotion of product, lifestyle, and industry in the same vehicle and by linking the medium directly to outside events that extended its reach. Could a similar vehicle market a smoke-free lifestyle as the key to success? Public health advocates should anticipate and challenge other new tobacco and tobacco industry marketing vehicles as communications technologies advance and public spaces for smoking shrink.

This research was supported by grants from the National Cancer Institute (CA76972) and by the University of California's Tobacco Related Disease Research Program (6RT0026). We

\section{What this paper adds}

Despite the documented health risks associated with cigar smoking, cigar sales increased during the late 1990 s by more than $50 \%$ amid a flurry of positive media coverage. During this time, two new cigar magazines, Cigar Aficionado and Smoke, appeared on US newsstands. We conducted a content analysis of Cigar Aficionado and Smoke magazines to learn more about what they contributed to the cigar use trend.

Cigar Aficionado and Smoke provided marketing platforms upon which repositioned visions of the cigar and the tobacco industry were built. The magazines normalised and promoted cigar use, rarely mentioned or minimised the seriousness of their threat to users' health, and implied that they were a constitutive element of a successful lifestyle. Although cigarette companies previously published giveaway marketing magazines, the cigar magazines were different because they appeared prominently on newsstands and made the tobacco product the focus of the entire magazine. Simultaneously marketing cigars and reinforcing the lifestyle associated with their use, they created a symbiosis between product and lifestyle and linked directly to outside events (such as cigar dinners) that extended the magazines' reach. Could a similar vehicle market a smoke-free lifestyle as the key to success? Public health advocates should anticipate and challenge other new tobacco and tobacco industry marketing vehicles as communications technologies advance and public spaces for smoking shrink.

thank Starley Shade for help with analysis. Parts of this paper were presented at the annual meeting of the American Public Health Association, November 1999, Chicago, Illinois.

1 Shanks TG, Burns DM. Disease consequences of cigar smoking. In: Cummings D, Hoffmann KM, ed. Cigars: health effects and trends. Bethesda, Maryland: US Department of Health and Human Services, 1998:105-58.

2 Iribarren C, Tekawa IS, Sidney S, et al. Effect of cigar smoking on the risk of cardiovascular disease, chronic obstructive pulmonary disease, and cancer in men. $N$ Engl $f$ Med tive pulmonary diseas

3 Repace JL, Ott WR, Klepeis NE. Indoor air pollution from cigar smoke. In: Cummings D, Hoffmann KM, eds. Cigars: health effects and trends. Bethesda, Maryland: US Department of Health and Human Services, 1998.

4 US Department of Agriculture. Tobacco situation and outlook report. Washington, DC: US Department of Agriculture, Commodity Economics Division, Economic Research Service, 1997

5 Pierce JP, Gilpin EA, Emery SL, et al. Tobacco control in California: who's winning the war? An evaluation of the tobacco control program, 1989-1996. La Jolla, California: University control program, 1989-1996. La J.

6 US Department of Health and Human Services. Youth use of cigars: patterns of use and perceptions of risk. Washington DC: cigars: patterns of use and perceptions of risk. Washington DC: Department of Health an

7 Malone RE, Bero LA. Cigars, youth and the internet link. Am F Public Health 2000;90:790-2.

8 Oxford English Dictionary online, 2nd ed. Oxford: Oxford University Press, 2000.

9 Beckett KC, Davison C. Lifecourse and lifestyle: the social and cultural location of health behaviors. Soc Sci Med 1995;40:629-38.

10 Giddens A. Modernity and self-identity: self and society in the late modern age. Oxford: Polity Press, 1991.

11 Houston M, Rothschild M, eds. Conceptual and methodological perspectives on involvement. Chicago: American Marketcal perspectives on invol

12 McLuhan M. Understanding media. The extensions of man. Toronto: McGraw Hill Book Company, 1964. 
13 Lee CS. Books of their own. Newsweek 1993;122(November $1)$.

14 Shanken M. A new men's lifestyle magazine. Cigar Aficionado Autumn 1992.

15 Audit Bureau of Circulations. Magazine publisher's statement for 6 months ended December 31, 1998: Cigar Aficionado, 1998

16 Mott G. Chat with Gordon Mott, executive editor. Cigar Aficionado 2000

17 Audit Bureau of Circulations. Magazine initial audit report for 6 months ended December 31, 1996: Smoke 1996

18 Klein A. The cigar caper: The shaping of an illusion. Baltimore Sun 1998, 11 January;1A.

19 McNichol T. Cigar asphyxionado. The New York Times 1997 29 June;34.

20 Sharp N. Informational fax on cigar sales. Washington DC: Cigar Association of America, 1999.

21 Wenger LD, Malone RE, Bero LA. The cigar revival and the popular press: a content analysis 1987-1997. Am f Public popular press: a content

22 SAS. SAS System for Windows, 6.12 version. Cary, North Carolina: SAS Institute Inc, 1996.

23 Suckling J. The world's best wrapper. Cigar Aficionado, Suckling J. The world's
Summer 1995:81-7.

24 Shanken M. An interview with Ernesto-Carrillo. Cigar Aficionado, May-June 1997:68-84

25 Anon. Le Cigar Noir lights up near you. Smoke, Spring 1997:48.
26 Suckling J. Viva Cohiba! Cigar Aficionado, August 1997:138-45.

27 Shanken M. A grandmother's habit. Cigar Aficionado, October 1997:48.

28 Shanken M. Models of moderation. Cigar Aficionado, April 1998:354.

29 Elkin EJ. More than a cigar. Cigar Aficionado, Winter 1994/ 95:124-34.

30 Weiss J. Just the facts: a doctor examines the links between coronas and coronaries. Cigar Aficionado, Winter 93/ 1994:205-6.

31 Shanken M. An interview with Edgar Cullman Jr. Cigar Aficionado, Autumn 1996:100-121.

32 Stover ME. Political statistics: an economist and statistician examines the scientific standards used in second-handsmoke studies. Cigar Aficionado, Autumn 1994:16.

33 Shanken M. Cigars are not for teenagers. Cigar Aficionado, October 1997:48.

34 Glantz SA. Preventing tobacco use-the youth access trap [editorial]. Am F Public Health 1996;86:156-8.

35 Lefton T, Adams M. Philip Morris pursuit of new media continues with Hachette men's mag project. Brandweek 1996(January 8): 1 .

36 Lefton T, Adams M. Philip Morris plans magazine. Mediaweek 1996;6(2):4-5.

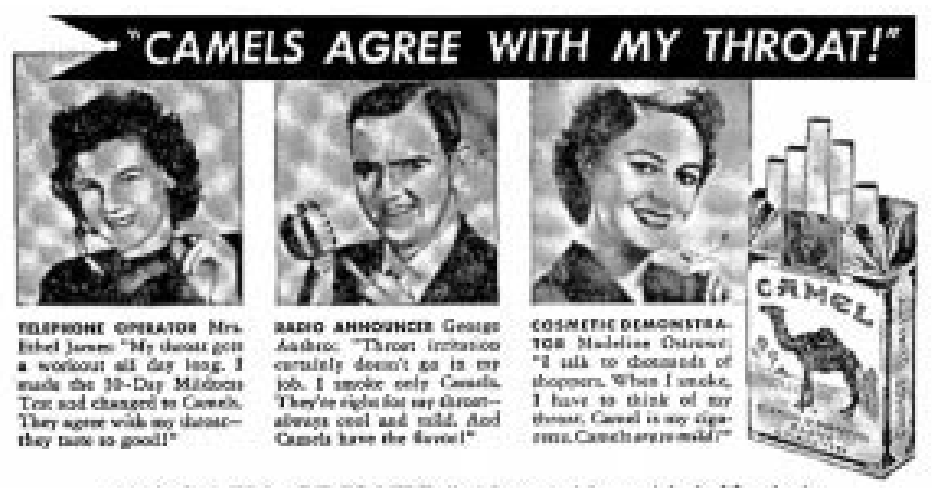

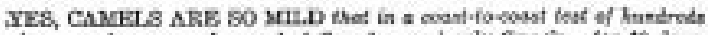

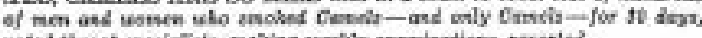

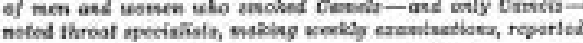

Not one single case of throat irritation due to smoking CAMELS

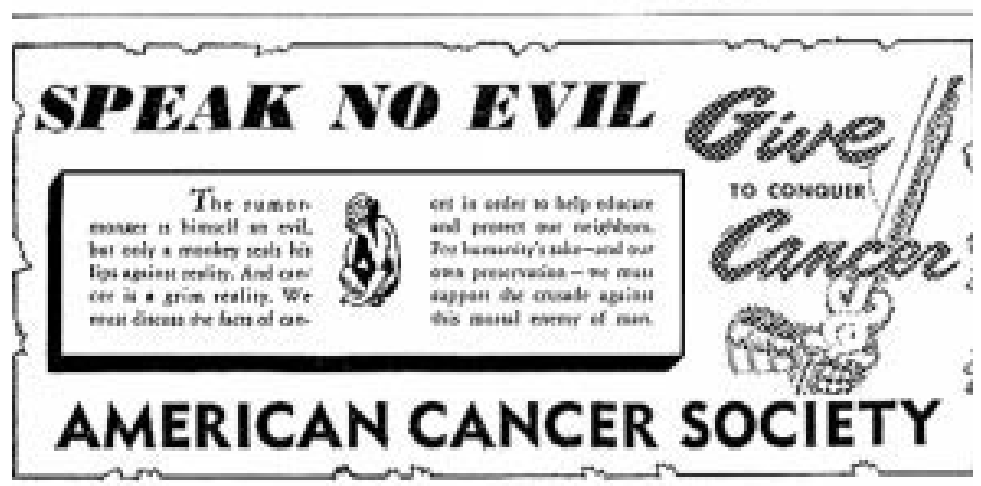

Niagara Journal [Niagara, Wisconsin] Apr 20, 1950, np.

Advertising product placement to die for. From the 1950s. Supplied by Rick Pollay, Vancouver. 